\title{
ВЛИЯНИЕ КОЛИЧЕСТВА БИОМАССЫ НА ОБРАЗОВАНИЕ НАНОЧАСТИЦ СЕРЕБРА ГРИБОМ SAССНAROMYCES ELLIPSOIDEUS BSU-XR1
}

\section{INFLUENCE OF BIOMASS QUANTITY ON THE FORMATION OF SILVER NANOPARTICLES BY SACCHAROMYCES ELLIPSOIDEUS BSU-XR1}

\section{S. Azadaliyeva \\ K. Ganbarov \\ M. Jafarov \\ S. Huseynova}

Summary. The aim of current study was to investigate the ability of silver nanoparticles formation by Saccharomyces ellipsoideus BSUXR1 depending on the biomass quantity. As a result of UV — VIS spectrophotometric analyses of the obtained reaction mixture, it has been determined that the high amount of nanoparticles was observed in range of 5-15g wet biomass. Yield of nanoparticles in $20 \mathrm{~g}$ biomass was very low. When specimens taken from each mixture were examined on a scanning electron microscope, the size of silver nanoparticles were found to be $8.63-16.9 \mathrm{~nm}$ in $5 \mathrm{~g}$ biomass, $17.2 \mathrm{~nm}$ in $10 \mathrm{~g}$ biomass and $22.4 \mathrm{~nm}$ in $15 \mathrm{~g}$ biomass. The formed silver nanoparticles were round shaped in all three specimens. X-ray spectroscopic analyses of the samples have demonstrated the specific adsorption peak (Ag Lal) for silver nanoparticles. It has been established that when the amount of wet biomass of Saccharomyces ellipsoideus BSU-XR1 increased from 5 to 15 $\mathrm{g}$ in the reaction mixture, the size of nanoparticles increased by 1.3-2.6 times. It was concluded that optimal biosynthesis of silver nanoparticles was obtained in $10 \mathrm{~g}$ of biomass.

Keywords: Saccharomyces ellipsoideus, biomass, silver nanoparticles, UV spectrophotometer, scannig electron microscope, $X$-ray spectroscope.

\author{
Азадалиева Саадат Фазаимовна \\ Докторант, Университет Одлар Юрду \\ azadeliyevaseadet@gmail.com \\ Ганбаров Худаверди Ганбарович \\ Д.б.н., профессор, Бакинский Государственный \\ Университет \\ Khuda1949@mail.ru \\ Джафаров Мирмуса Миришович \\ Д.б.н., профессор, Бакинский Государственный \\ Университет \\ Cafarov67@mail.ru \\ Гусейнова Санам Исмаиловна \\ Д.философии по биологии, Бакинский \\ Государственный Университет \\ aliyevasenem@mail.ru
}

Аннотация. Целью настоящего исследования было изучение возможности образования наночастиц серебра дрожжевом грибом Saccharomyces ellipsoideus BSU-XR1 в зависимости от количества биомассы. В результате спектрофотометрического анализа UV-VIS полученной реакционной смеси было определено, что высокое количество наночастиц наблюдалось в диапазоне 5-15 г влажной биомассы. Выход наночастиц при 20 г биомассы был очень низким. Образцы, взятые из каждой смеси, были исследованы на сканирующем электронном микроскопе и показано, что размер наночастиц серебра составляет 8,63-16,9 нм при 5 г биомассы, 17,2 нм при 10 г биомассы и 22,4 нм при 15 г биомассы. Во всех трех вариантах наночастицы имели округлую форму. Рентгеноспектральный анализ образцов продемонстрировал специфический пик адсорбции (Ag Lal) для наночастиц серебра. Установлено, что при увеличении количества влажной биомассы гриба Sac. ellipsoideus BSU-XR1 в реакционной смеси с 5 до 15 г размер наночастиц увеличивался в 1,3-2.6 раза. Был сделан вывод, что оптимальный биосинтез наночастиц серебра происходит при 10 г биомассы.

Ключевые слова: Saccharomyces ellipsoideus, биомасса, наночастицы серебра, УФ-спектрофотометр, сканирующий электронный микроскоп.

больше внимания благодаря своей оптимальной площади поверхности, уникальным физическим, химическим и биологическим свойствам (Monteiro et al., 2012; Atef et al., 2013; Roberto et al., 2014; Shailesh et al., 2015).

Известно, что виды рода Saccharomyces широко используются в домашнем хозяйстве, выпечке хлеба, производстве пива и вина. Они были одним из ингредиентов нашей еды с древних времен. Поэтому получение наночастиц из этих грибов совершенно безвредно для 


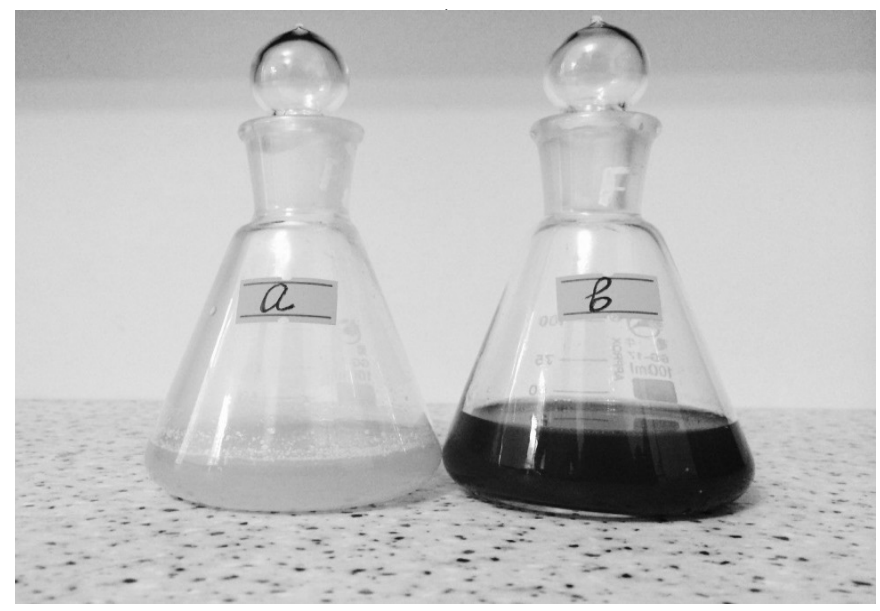

Рис. 1. Потемнение цвета реакционной смеси во время инкубации с биомассой Saccharomyces ellipsoideus BSU - XR1. A - контроль; Б - опыт

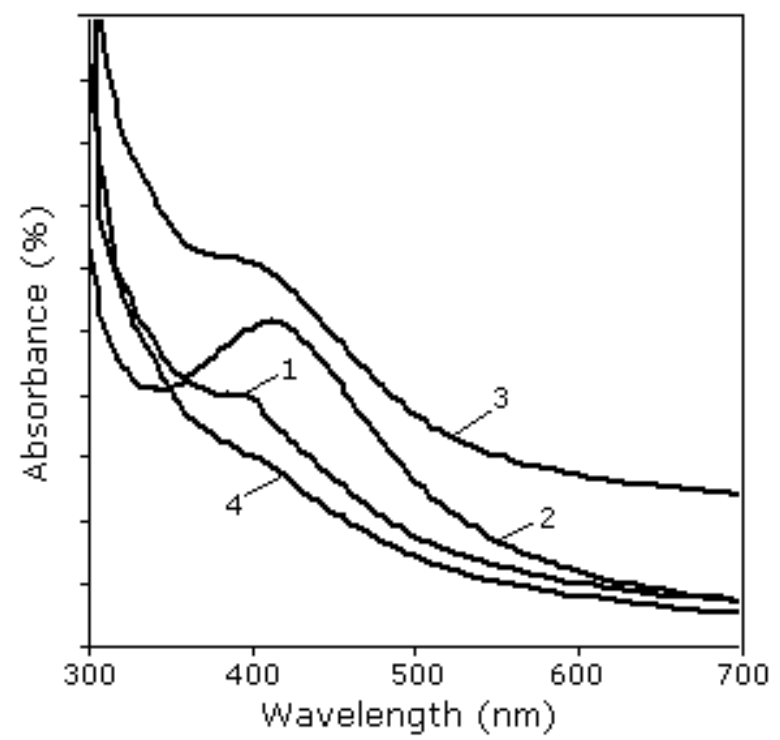

Рис. 2. УФ-спектр образующихся наночастиц серебра в зависимости от количества биомассы Saccharomyces ellipsoideus BSU —XR1. Биомасса: 5 г (1); 10 г (2); 15 г (3) и 20 г (4).

людей, работающих в технологическом процессе. В связи с этим виды рода Saccharomyces были использованы для получения наночастиц серебра и золота (Fengjiao et al., 2013; Kaler et al., 2013; Sahib et al., 2017). Также сообщалось о антибактериальной активности Saccharomyces cerevisae в отношении патогенных бактерий (Niknejad et. al., 2015; Korbekandi et al., 2016; Sheik et al., 2016).

В предыдущих работах нами определены свойства образования наночастиц серебра у Saccharomyces ellipsoideus BSU-XR1. Изучено влияние температуры (Джафаров и др., 2018) и инкубационного периода (Азадалиева и др., 2018) на образование наночастиц сере- бра у данного штамма. Основная цель данного исследования - определить влияние количества биомассы на образование наночастиц серебра у Saccharomyces ellipsoideus BSU -XR1.

\section{Материалы и метолы}

Дрожжевой гриб Saccharomyces ellipsoideus BSU XR1 был взят из коллекции культур кафедры микробиологии Бакинского государственного университета. Гриб культивировали в оптимальной питательной среде (сахароза - 20 г, пептон - 10 г дрожжевой экстракт - 10 г, дистиллированная вода - 1 литр) при температуре $30^{\circ} \mathrm{C}$ 


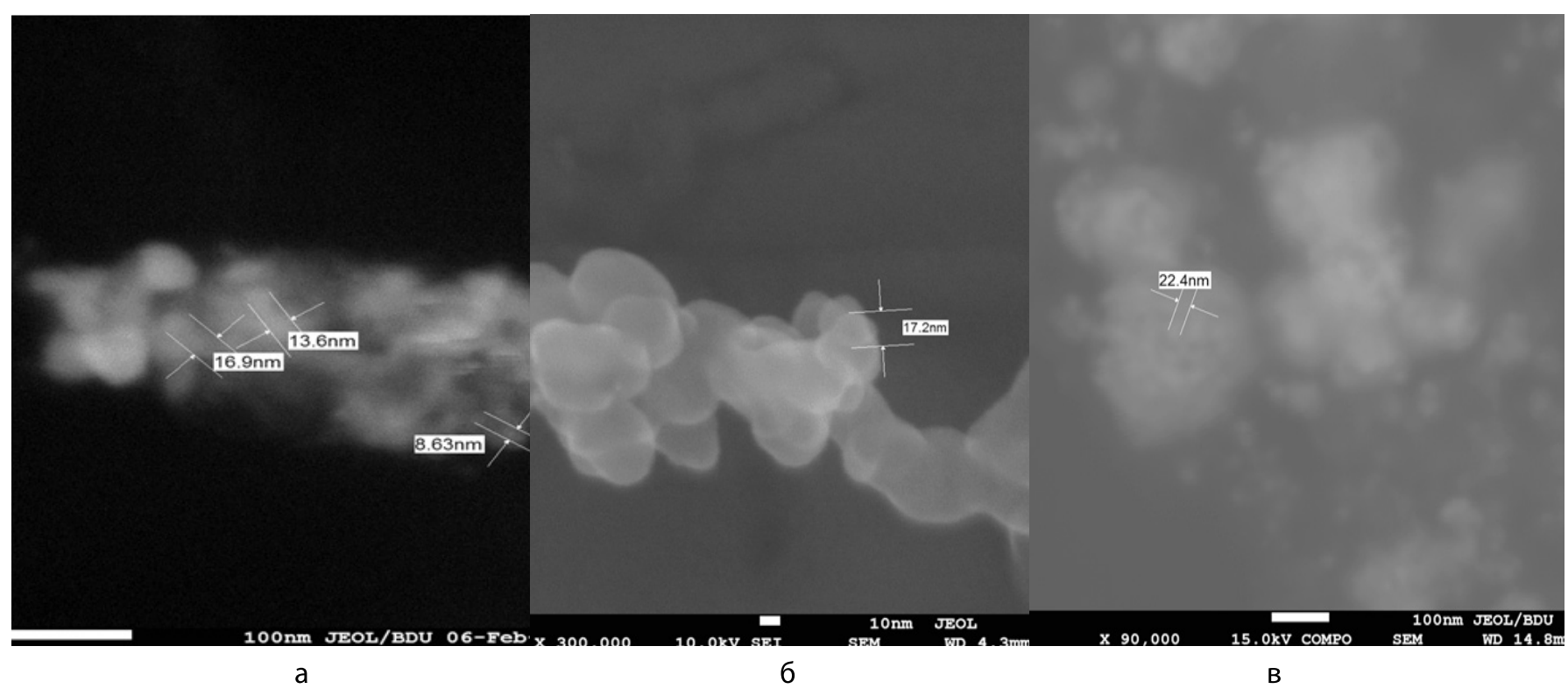

Рис. 3. Наночастицы серебра на сканирующем электронном микроскопе, сформированные в различных количествах биомассы Saccharomyces ellipsoideus BSU - XR1. Биомасса: 5 г (a); 10г (б); 15г (в).

для получения биомассы. Полученную биомассу отделяли фильтрованием и трижды промывали стерильной дистиллированной водой. Готовили суспензию добавлением 90 мл стерильной дистиллированной воды к 5 г, 10 г, 15 г и 20 г собранной влажной биомассы. В каждый вариант опыта добавляли по 10 мл 10-3 молярного раствора $\mathrm{AgNO}_{3}$. Смесь инкубировали в темноте в течение 7 дней при температуре $30^{\circ} \mathrm{C}$.

Образование наночастиц серебра в первую очередь было визуализировано по изменению цвета реакционной смеси от светло-желтого до темно-коричневого. Образцы из реакционных смесей анализировали на спектрофотометре «UV - VIS specific 250 plus». Форму и размер наночастиц серебра определяли на сканирующем электронном микроскопе (JEOL 7600F, Япония). Рентгеноспектральный анализ образцов осуществляли на энергодисперсионной рентгеновской спектроскопии (EDS).

\section{Результаты \\ и их обсу> $\Delta е н и е$}

Полученные результаты показали, что цвет реакционной смеси, содержащей влажную биомассу гриба Saccharomyces ellipsoideus BSU - XR1 в количестве 5 г, 10 г 15 г, 20 г, усиливался (затемнялся) во время инкубации (Рис. 1). В тех же условиях в контрольной колбе (без раствора $\mathrm{AgNO}_{3}$ ) изменения цвета не наблюдалось. Потемнение цвета реакционной смеси было принято как первоначальный признак присутствия наночастиц серебра.
УФ-спектрофотометрический анализ образцов показал поглощение в диапазоне 400-420 нм, что характерно для наночастиц серебра. В образцах с биомассой 5 г, 10 г и 15 г, поглощения в УФ области были при длине волны 400 нм, 420 нм и 415 нм, соответственно (Рис. 2). Небольшую разность в длине вольны погашения, возможно связана с образованием кластеров наночастиц разного размера. В образце с биомассой 20 г образование наночастиц было незначительно.

Результаты анализа образцов в сканирующим электронном микроскопе показали, что наночастицы серебра имеют сферическую форму и переменный размер. Размер наночастиц менялся в зависимости от количества биомассы. Так, размер наночастиц, продуцируемых в образце с 5 г биомассы, составлял 8,6-16,9 нм, с 10 г биомассы - 17,2 и с 15 г биомассы - 22,4 нм (Рис. 3). Следовательно, при увеличении количества биомассы размер образующихся наночастиц серебра также увеличивался.

Известно, что при увеличении количества биомассы плесеневым грибом Aspergillus terreus MRCCG 92 размер образующихся наночастиц серебра уменьшался. Увеличение количества биомассы привело к уменьшению размера наночастиц в 1,7 раза (Narayanan, Sukthivel, 2010). Однако результаты, полученные нами с дрожжевым грибом Saccharomyces ellipsoideus BSU - XR1, противоречили результатам, полученным для плесневого гриба Aspergillus terreus MRCCG 92. Трехкратное (с 5 г до 15 г) увеличение количества биомассы дрожжевого 


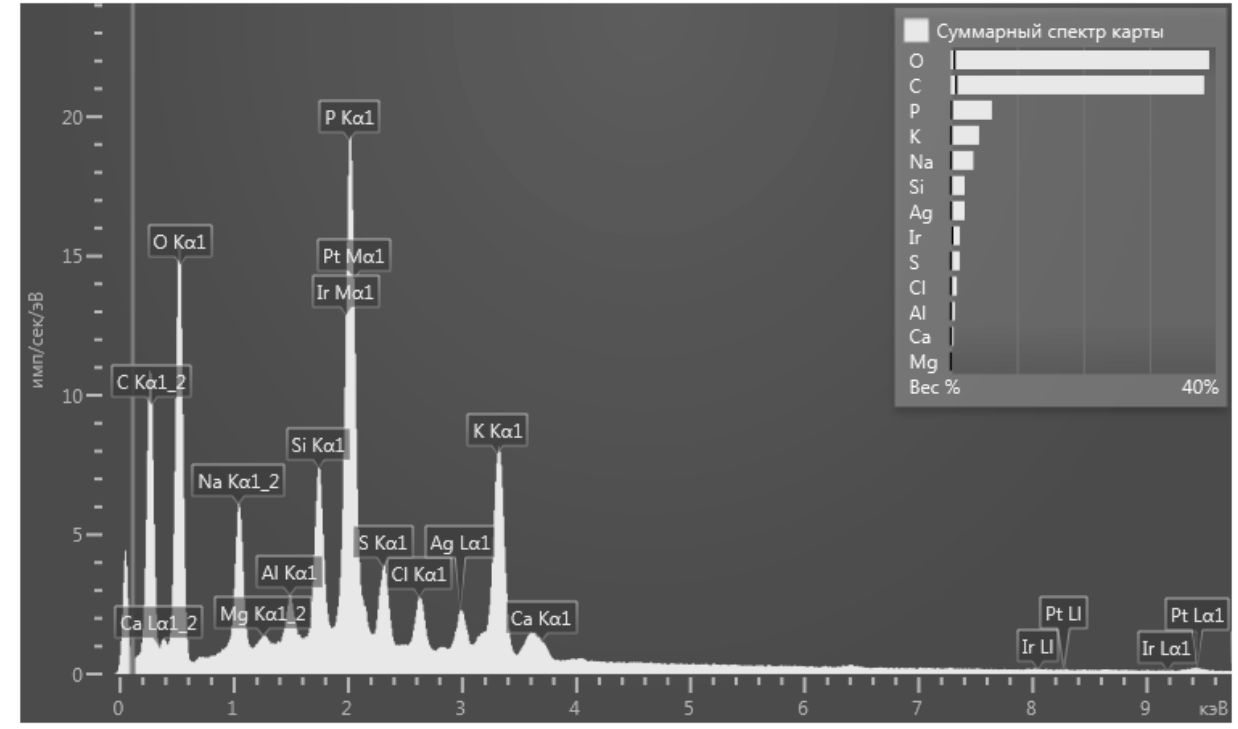

a

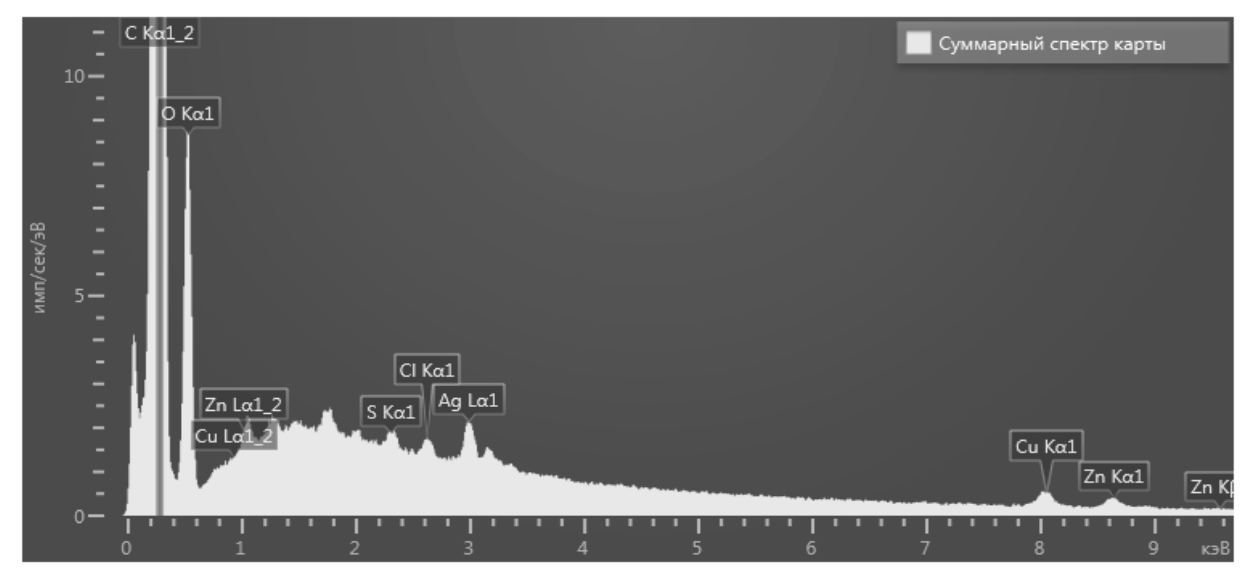

6

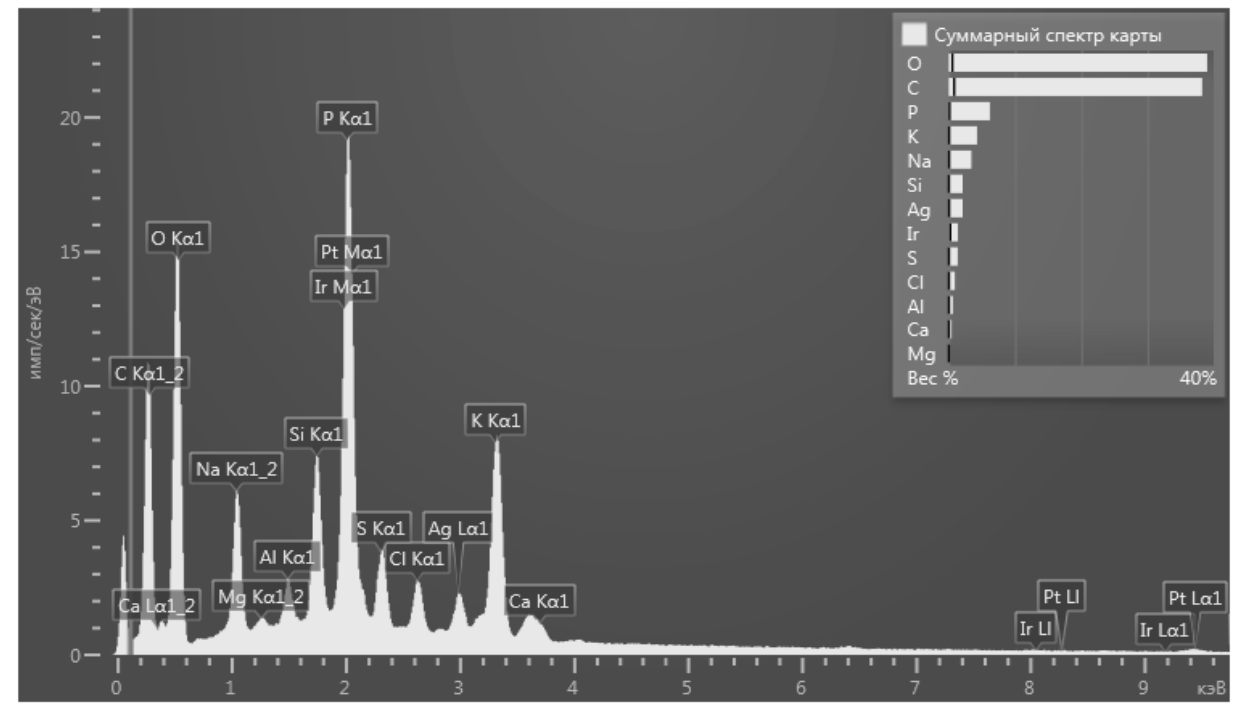

B

Рис. 4. Характерный рентгеновский спектр наночастиц серебра, образованных в разных количествах биомассы дрожжевого гриба Saccharomyces ellipsoideus BSU — XR1. Биомасса: 5 г (а); 10г (б); 15 г (в). 
гриба Sac.ellipsoideus BSU-XR1 привело к увеличению размера наночастиц серебра в 1.3-2,6 раза. Причина противоположного характера изменения размера образующихся наночастицах серебра в зависимости от количества биомассы у разных грибов труднообъяснима. Скорее всего, это явление связано с особенностями используемых видов грибов.

В рентгеновском спектре используемых трех образцов (5 г, 10 г и 15 г биомассы) отмечен пик AgLa1, характерный для наночастиц серебра (Рис. 4).
Таким образом, УФ-спектрометрический анализ образцов показал поглощение в диапазоне 400-420 нм, что характерно для наночастиц серебра. При увеличении количества биомассы дрожжевого гриба Saccharomyces ellipsoideus BSU - XR1 в реакционной смеси с 5 г до 15 г размер наночастиц также увеличивается в 1,3-2,6 раза. По характерному рентгеновскому спектру наночастицы выглядят как серебро. Оптимальная биомасса для образования наночастиц серебра с помощью Saccharomyces ellipsoideus BSU - XR1 оказалась 10 г биомассы.

\section{ЛИТЕРАТУРА}

1. Азадалиева С., Джафаров М., Агамалиев 3., Эйвазова Г., Ганбаров Х. Влияние инкубационного периода на биоситез нанчастиц серебра у дрожжевого грибa Saccharomyces ellipsoideus BSU — XR1 // Научные труды Института Микробиологии НАН Азербайджана, 2018, том 16, № 1, с. 42-47

2. Джафаров М., Азадалиева С., Гусейнова С., Эйвазова Г. Влияние температуры на биосинтез наночастицы серебра у дрожжевого гриба Saccharomyсеs ellipsoideus BSU — XR1 // Материалы Международной научной конференции «Современные естественные науки». Гянджа, 2018, ч. 2, с. 293-299.

3. Atef H., Mogda K., \& Mahmoud H. Biosynthesis of silver nanoparticles (Ag-Nps) (a model of metals) by Candida albicans and its antifungal activity on some fungal pathogens // New York Science Journal,2013, 6, 27-33.

4. Bharde A., Rautaray D., Bansal V., Ahmad A., Sarkar I., Yusuf S., Sanyal, M., \& Sastry M. Extracellular Biosynthesis of Magnetite using Fungi // Biosynthesis of Nanoparticles,2006, 2, 135.

5. Fengjiao H., Li Z., Gao F., \& Yang Z. Extracellular biosynthesis of Ag nanoparticles by commercial baker's yeast // Advanced materials research, 2013, 785, 370-373.

6. Ganbarov Kh. Ahmadov I.S., Ramazanov M.A., Musayev E.M., Eyvazova G.S., Aghamaliyev Z.A. Silver nanoparticles synthesized by the Azerbaijanian environmental isolated //Aspergillus niger. Jour. Microbiol. Biotechnol. Food Sciences, 2014a, 4, 137-141.

7. Ganbarov Kh. Ahmadov I.S., Ramazanov M.A., Musayev E.M., Eyvazova G.S., Aghamaliyev Z.A. The concentration effect of the formation of silver nanoparticles by the mold fungus Aspergillus niger BDU A4 // Jour. Biotechnol, 20146,185, 28.

8. Jafarov M.M., Bozkurt K.J., Seyidova K.Q., Huseynova, S.I., Agamaliyev Z.A., \& Eyvazova M.A. Formation of silver nanoparticles in the cultural fluid by Candida guillermondii BSU — 217 yeast fungi stamp // Transaction of the Institute of Microbiology of Azerbaijan National Academy of sciences, 2017, 15, 214-219.

9. Kaler A., Jain S., \& Banerjee U.C. Green and rapid synthesis of anti-cancerous Silver Nanoparticles by Saccharomyces boulardii and Insight into Mechanism of Nanoparticles Synthesis // Hindawi Publishing Corporation BioMed Research International,2013, 112-119.

10. Korbekandi H., Mohseni S., Jouneghani R.M., \& Iravani S. Biosynthesis of silver nanoparticles using Saccharomyces cerevisiae artificial cells // Nanomedicine and Biotechnology,2016, 44, 235-239.

11. Li X., Xu H., \& Chen G. Biosynthesis of Nanoparticles by Microorganisms and Their Applications // Journal of nanomaterials, 2011, 2, 1-17.

12. Monteiro D.R., Silva S.C., \& Negri M. Effect of silver nanoparticles against Candida albicans and Candida glabrata biofilms // Lett. Appl. Microbiol, $2012,54,381-391$.

13. Narayanan K.B., and Sakthivel N. Biological synthesis of metal nanoparticles by microbes // Advances in Colloid and Interface Science, 2010, 2, 1-13.

14. Niknejad F., Nabili M., Ghazvini R., \& Moazeni M. Green synthesis of silver nanoparticles: Advantage of the yeast Saccharomyces cerevisiae model // Curr. Med.Mycol, 2015,1, 17-24.

15. Roberto V., Miguel A., Ernestina C. Ultrastructural analysis of Candida albicans when exposed to silver nanoparticles // Plos 0ne, 2014, 9, 1-10.

16. Sadowski Z. Synthesis of silver nanoparticles using microorganisms // Materials Science, 2008, 26, 420-424.

17. Sahib F.H., Aldujaili N.H., \& Alrufae M.M. Biosynthesis of silver nanoparticles using Saccharomyces boulardii and study their biological activities // European journal of pharmaceutical and medical research, 2017, 4, 65-74.

18. Shailesh R.W., Mullaş M.N., Marathe S.R., \& Sonawane K.D. Ecofriendly production of silver nanoparticles using Candida utilis and its mechanistic action against pathogenic microorganisms // Biotech, 2015,1,33-38.

19. Sheik M., Badhusha M., \& Mohideen M.M.A. Biosynthesis of silver nanoparticles using Saccharomyces cerevisiae with different pH and study of antimicrobial activity against bacterial pathogens // Chemical Science Transactions, 2016, 5, 906-911.

20. Zhang S. \& Crow S.A. Toxic Effects of $\mathrm{Ag}(\mathrm{I})$ and $\mathrm{Hg}(\mathrm{II})$ on Candida albicans and C. maltosa: a Flow Cytometric Evaluation // Applied and Environmental Microbiology, 2001, 67, 4030-4035.

( А Азадалиева Саадат Фазаимовна ( azadeliyevaseadet@gmail.com ), Ганбаров Худаверди Ганбарович ( Khuda1949@mail.ru ), Джафаров Мирмуса Миришович ( Cafarov67@mail.ru ), Гусейнова Санам Исмаиловна ( aliyevasenem@mail.ru ).

Журнал «Современная наука: актуальные проблемы теории и практики» 